\title{
Probiotic effect on Helicobacter pylori attachment and inhibition of inflammation in human gastric epithelial cells
}

\author{
HANYI SONG ${ }^{1}$, LONG ZHOU ${ }^{2}$, DONGYAN LIU ${ }^{3}$, LIHUI GE ${ }^{1}$ and YAN LI ${ }^{1}$ \\ Departments of ${ }^{1}$ Gastroenterology and ${ }^{2}$ Orthopedics; ${ }^{3}$ Medical Research Center, \\ Shengjing Hospital of China Medical University, Shenyang, Liaoning 110004, P.R. China
}

Received June 17, 2018; Accepted April 18, 2019

DOI: $10.3892 /$ etm.2019.7742

\begin{abstract}
Helicobacter pylori (H. pylori) is a major cause of chronic gastritis, gastric ulcers and gastric cancer. Recent studies have identified that probiotics are beneficial to human health due, in part, to their anti- $H$. pylori activities. Therefore, the present study investigated the antagonistic and local immunoregulatory activities of seven commercial probiotic strains and explored their mechanisms of actions. The human gastric epithelial cell line-1 (GES-1) was used to assess the effects of probiotics on the adhesion ability of $H$. pylori. GES-1 cells were infected with $H$. pylori plus lipopolysaccharide (HP-LPS) or the drug-resistant $H$. pylori strain (HP021) in the presence or absence of live probiotics. Following this, the growth rate and the adhesion ability of GES-1 cells were detected using MTT and urease activity assay. Toll-like receptor 4 (TLR4), NFKB inhibitor- $\alpha$ (IкB $\alpha)$ and nuclear factor (NF)- $\mathrm{\kappa B}$ levels were measured by western blot analysis. The amount of interleukin (IL)-8 in the cell culture medium was determined by ELISA. Amongst the seven probiotic strains studied, live Lactobacillus acidophilus (L. acidophilus) and Lactobacillus bulgaricus (L. bulgaricus) inhibited $H$. pylori adherence to GES-1 cells most significantly. L. bulgaricus inhibited IL-8 production by GES-1 cells through modulation of the TLR4/I $\kappa \mathrm{B} \alpha / \mathrm{NF}-\kappa \mathrm{B}$ pathway. Therefore, the present results suggested that consumption of food containing L.acidophilus and L. bulgaricus may be used as an adjuvant therapy for $H$. pylori-associated gastritis.
\end{abstract}

\section{Introduction}

Helicobacter pylori (H. pylori) was originally isolated from the gastric mucosa of patients with chronic active gastritis in 1983 with further study revealing that the pathogen itself

Correspondence to: Dr Yan Li, Department of Gastroenterology, Shengjing Hospital of China Medical University, 36 Sanhao Street, Heping, Shenyang, Liaoning 110004, P.R. China

E-mail: yanli0227@hotmail.com

Key words: Helicobacter pylori, probiotics, cell adhesion, inflammation, lipopolysaccharide caused the condition (1). H. pylori infects $>50 \%$ of the world's population (2) and it frequently causes chronic active gastritis, gastroduodenal ulcers (3) and gastric cancer (4). H. pylori is occasionally associated with functional dyspepsia, unexplained iron deficiency anemia (5) and idiopathic thrombocytopenic purpura (6). The standard triple therapy used to treat $H$. pylori is a proton pump inhibitor (PPI) in conjunction with a 7-10 day course of two antibiotics. This protocol eradicates $H$. pylori infection in $\sim 80 \%$ of patients (7). Bismuth-based quadruple therapies, including clarithromycin, amoxicillin and metronidazole, are another alternative treatment $(8,9)$. However, some strains of $H$. pylori demonstrate antibiotic-resistance, which complicates treatment. In addition, the neurotoxicity of bismuth limits its use in the elderly and children (10). Copious use of antibiotics is not only accompanied by a variety of side effects, but also increases the risk of antibiotic resistance. Therefore, the development of safer and more effective new therapeutic agents targeting $H$. pylori is an important focus of current research. Recent studies have demonstrated that administration of oral probiotics is greatly beneficial for the treatment of $H$. pylori infection (11-13). The substances produced by probiotics significantly inhibit VacA and flaA virulence genesin $H$. pylori (12). Use of probiotics alongside drugs often reduces the drug side effects and attenuates the gastric mucosal inflammation $(14,15)$. It has been reported that Lactobacillus salivarius (L. salivarius), Lactobacillus gasseri, Lactobacillus casei Shirota, Lactobacillus Johnsonii La1, Lactobacillus rhamnosus $G G$ and Saccharomyces boulardii have either anti-H. pylori activities or anti-inflammatory properties $(16,17)$. The antagonistic activities of probiotics against $H$. pylori are strain-specific; however, their mechanisms of action remain unclear (18).

Currently, mixed strain probiotics are the most-widely studied (8). Different strains of probiotics may possess synergetic or antagonistic effects. In the present study, the anti-H. pylori activities of Lactobacillus acidophilus (L. acidophilus), L. salivarius, Clostridium butyricum (C. butyricum), Bacillus licheniformis (B. licheniformis), Bifidobacterium infantis (B. infantis), Bifidobacterium longum (B. longum) and Lactobacillus bulgaricus (L. bulgaricus) were evaluated. These probiotic strains are widely used in clinical settings to treat diarrhea and have been reported to improve the eradication rate of $H$. pylori in some clinical cases due to the secretion of antibacterial substances including lactic acid, 
acetic acid and hydrogen peroxide $(19,20)$. The present study objective was to evaluate the probiotic mechanisms of action against $H$. pylori with the results potentially providing a new theoretical basis for eradicating H. pylori.

\section{Materials and methods}

Bacterial strains and culture conditions. The probiotic strains used were as follows: L. acidophilus, L. salivarius, C. butyricum, B. licheniformis, B. infantis, B. longum and L. bulgaricus, purchased from Siliankang, Jinshuangqi, Changlekang and Taiwan Yaxin (Table I). The probiotics were cultured on De Man, Rogosa and Sharpe agar plates (MRS; Oxoid; Thermo Fisher Scientific, Inc.) at $37^{\circ} \mathrm{C}$ in an anaerobic humidified environment for $24 \mathrm{~h}$. Live bacteria cells were obtained by centrifuging the cultures and washing with sterile PBS three times. The precipitate were resuspended with RPMI 1640 medium (Gibco; Thermo Fisher Scientific, Inc.) and adjusted to $3 \times 10^{8}$ colony-forming units (CFU) $/ \mathrm{ml}$.

H. pylori ATCC 43504 strain was purchased from the American Type Culture Collection and the multidrug resistant H. pylori strain (HP021) was isolated from the gastric biopsy of a patient with chronic atrophic gastritis and confirmed to have resistance to clarithromycin and levofloxacin. H. pylori ATCC43504 strain expresses CagA and VacA proteins, which induces nuclear factor (NF)- $\mathrm{kB}$ and interleukin (IL)-8 expression (21). Both $H$. pylori strains were grown on Columbia blood agar plates supplemented with 7\% defibrinated horse blood (Beijing Biotek Medical Device, Ltd.) for at least 3 days at $37^{\circ} \mathrm{C}$ under microaerophilic conditions $\left(5 \% \mathrm{O}_{2}, 10 \% \mathrm{CO}_{2}\right.$, and $85 \% \mathrm{~N}_{2}$ ). Normal human gastric epithelial GES-1 cells (American Type Culture Collection) were cultured at $37^{\circ} \mathrm{C}$ in RPMI 1640 medium supplemented with $10 \%$ fetal bovine serum (Biological Industries) and $100 \mu \mathrm{g} / \mathrm{ml}$ penicillin/streptomycin in a humidified atmosphere with $5 \% \mathrm{CO}_{2}$. The medium was changed every other day. Before experiments were initiated, the cells were plated in 96 -well plates at $5 \times 10^{3}$ cells/well or $2.5 \times 10^{5}$ cells/well in 6 -well plates for $24 \mathrm{~h}$ in serum-free RPMI-1640 medium.

Cell-free supernatant (CFS) preparation and H. pylori ATCC43504-lipopolysaccharide (LPS) culture. Cultures of the various probiotic strains were grown in MRS broth (Oxoid; Thermo Fisher Scientific, Inc.) in an anaerobic humidified environment at $37^{\circ} \mathrm{C}$ for $96 \mathrm{~h}$. CFS from the probiotics was prepared by centrifuging $\left(12,000 \mathrm{x} \mathrm{g} ; 4^{\circ} \mathrm{C} ; 10 \mathrm{~min}\right)$ the respective MRS broths. CFS were filtered through a $0.2 \mu \mathrm{M}$ filter and stored at $-20^{\circ} \mathrm{C}$.

Culture broth from H. pylori ATCC43504 was centrifuged $\left(8,000 \mathrm{x} \mathrm{g} ; 4^{\circ} \mathrm{C} ; 10 \mathrm{~min}\right)$ and washed three times then resuspended in PBS. H. pylori lipopolysaccharide (HP-LPS) was obtained using an LPS extraction kit (Intron Biotechnology, Inc.) according to the manufacturer's instructions. HP-LPS concentrations were determined with a kinetic Limulus Amebocyte Lysate Assay kit (Xiamen Limulus Reagent Biotechnology Co., Ltd.).

GES-1 cell viability. Probiotics and CFS are toxic to GES-1 cells at high concentrations and during long incubations (17). To determine the optimal concentration and incubation time for each probiotic and CFS, GES-1 cells were infected with CFS and probiotics at multiplicities of infection (MOI) of 100 and 1,000 in antibiotic-free RPMI 1640 medium at $37^{\circ} \mathrm{C}, 5 \%$ $\mathrm{CO}_{2}$ for up to $8 \mathrm{~h}$. Viable GES-1 cell numbers were determined by trypan blue staining following incubation for 2, 4, 6 and $8 \mathrm{~h}$ at $37^{\circ} \mathrm{C}$. Non-infected cell cultures served as controls. Cells that were not stained with trypan blue were counted as viable cells.

GES-1 proliferation. GES-1 cells were seeded into 96-well plates at $1.5 \times 10^{5} \mathrm{cells} / \mathrm{ml}$ in $100 \mu \mathrm{l}$ culture volume for $24 \mathrm{~h}$. CFS $(100 \mu \mathrm{l})$ and probiotics were then added to the GES-1 cells at $10^{2}, 10^{3}, 10^{4}, 10^{5}, 10^{6}, 10^{7}, 10^{8}$ and $10^{9} \mathrm{CFU} / \mathrm{ml}$. Each condition was performed in triplicate and cultured for $24 \mathrm{~h}$. Cells were washed three times with sterile PBS solution then $20 \mu \mathrm{l}$ of $4 \mathrm{mg} / \mathrm{ml}$ MTT reagents was added. The cells were cultured for another $4 \mathrm{~h}$ and then centrifuged for $5 \mathrm{~min}$ at $800 \mathrm{x}$ g. The supernatant was discarded and $150 \mu 1$ dimethyl sulfoxide was added. Absorbance was measured at $490 \mathrm{~nm}$.

Assessment of adhesion ability. Adhesion ability of probiotics on GES-1 cells was determined as previously described by de Klerk et al (22). In brief, probiotics were suspended in RPMI-1640 medium to a concentration of $3 \times 10^{8} \mathrm{CFU} / \mathrm{ml}$. GES-1 cells cultured on slides in 6-well plates were infected with probiotics at a MOI of 100 . Following $4 \mathrm{~h}$ of incubation, each well was washed three times with sterile PBS to remove any unbound bacteria. Cells were fixed with $4 \%$ paraformaldehyde at room temperature for $30 \mathrm{~min}$ and then the bacteria were Gram stained at room temperature for $5 \mathrm{~min}$. The cell monolayer was washed with tap water and the cells were observed at a magnification of $\mathrm{x} 1,000$ under light microscope oil immersion. The adherence of probiotics was calculated as previously described $(23,24)$ and was as follows: Cell adhesion index=number of adhering probiotics/total number of cells in the field of view $x 100$. Cell adhesion rate=number of cells adhered by probiotics/total number of cells in the field of view x100. Cell adhesion index indicates the number of probiotics adhering to each cell, and cell adhesion rate represents the proportion of cells adhered by probiotics in total cells.

Inhibition of H. pylori growth. H. pylori ATCC43504 and HP021 were evenly seeded on Columbia agar plates without antibiotics. Holes were introduced to the agar plates with a sterile oxford cup then the bottom of holes were sealed with $0.8 \%$ agar liquid. Live probiotics $\left(120 \mu 1\right.$ at $\left.3 \times 10^{9} \mathrm{CFU} / \mathrm{ml}\right)$ were suspended in MRS broth and CFS (120 $\mu \mathrm{l})$ was added to the holes in the plates. The plates were incubated under microaerophilic conditions for $72 \mathrm{~h}$ at $37^{\circ} \mathrm{C}$, and then the diameters of the inhibition zones were measured. PBS and MRS medium were used as negative controls.

Adhesion of H. pylori to GES-1 cells. For the infection studies, GES-1 cells were grown on microtiter plates to form a confluent monolayer. The concentration of each probiotic was adjusted to $1.5 \times 10^{7} \mathrm{CFU} / \mathrm{ml}$. H. pylori ATCC43504 and HP021 concentrations were then adjusted to $1.5 \times 10^{7} \mathrm{CFU} / \mathrm{ml}$. GES-1 cells were pre-treated with $50 \mu 1$ of live probiotics for $2 \mathrm{~h}$ before infection (pre-treated group) or following infection 
(post-treated group). GES-1 cells were infected for $2 \mathrm{~h}$ with $50 \mu \mathrm{l}$ of live H. pylori ATCC43504 or HP021. Subsequently, each well was washed three times to remove any non-adherent H. pylori. Urease activity was determined using a modified phenol red method $(18,25,26)$. In brief, $200 \mu 1$ of urease test solution $(20 \%[\mathrm{w} / \mathrm{v}]$ urea and $0.012 \%$ phenol red in phosphate buffer; $\mathrm{pH}$ 7.0) was added to each well of a microtiter plate. The plate was then incubated at $37^{\circ} \mathrm{C}$ for $1 \mathrm{~h}$. The absorbance at $550 \mathrm{~nm}$ was measured with a microtiter plate spectrophotometer (BioTek Instruments, Inc.). The adherence of $H$. pylori was calculated as described by Chen et al (18) and was as follows: Adherence $=([\mathrm{Optical}$ density experimental-optical density negative]/[optical density positive-optical density negative] x100.

The negative control contained only GES- 1 cells and the positive control contained both GES-1 cells and H. pylori, which were used to establish $100 \%$ adherence.

ELISA for interleukin (IL)-8 detection. LPS is a pathogenic factor of $H$. pylori which can induce GES-1 cells to produce IL-8 (27). Probiotics with proven adhesive ability were added to GES-1 cells (MOI of 100) and incubated for $2 \mathrm{~h}$. Following washing with PBS to remove bacilli, HP-LPS (final concentration of 7,000 endotoxin units [EU]/ml) was added and the cells were incubated for another $6 \mathrm{~h}$. The final culture supernatants were centrifuged for $10 \mathrm{~min}$ at $12,000 \mathrm{x} \mathrm{g}$ and $4^{\circ} \mathrm{C}$ to remove bacteria and cell debris. Supernatants were then aliquoted and stored at $-80^{\circ} \mathrm{C}$. IL- 8 concentration in the supernatant was determined using a commercially available ELISA kit (cat. no. VAL103; R\&D Systems, Inc.). Absorbance values were measured at $450 \mathrm{~nm}$ using a microplate reader. Each sample was measured three times.

Preparation of cellular lysates and western blot analysis. GES-1 cells were pre-treated for $2 \mathrm{~h}$ with probiotics, followed by HP-LPS stimulation for 60 or $120 \mathrm{~min}$ at a final concentration of 7,000 EU/ml. Cytoplasmic and nuclear extracts were then isolated using a Nuclear Extract kit (Active Motif, Inc.). Protein concentrations were determined with an enhanced bicinchoninic acid protein assay kit.

Each extract was mixed with $x 5$ loading buffer and boiled for $5 \mathrm{~min}$. The extracted proteins were then aliquoted and stored at $-80^{\circ} \mathrm{C}$. A total of $30 \mu \mathrm{g}$ of protein was loaded into each lane, separated via $8 \%$ SDS-PAGE and then electrotransferred to a polyvinylidene difluoride membrane. Membranes were blocked at room temperature with $5 \%$ fat-free dried milk in Tris buffered saline containing $0.1 \%$ Tween-20 (TBST) for $2 \mathrm{~h}$. Following this, membranes were incubated overnight at $4^{\circ} \mathrm{C}$ with primary antibodies anti-toll-like receptor 4 (TLR4; cat. no. AF1478-SP; 1:1,000; R\&D Systems, Inc.), anti-NF-кB p65 (cat. no. 8242P; 1:1,000; Cell Signaling Technology, Inc.), and anti-NFKB inhibitor- $\alpha$ (IкB $\alpha$; cat. no. 4814P; 1:1,000; Cell Signaling Technology, Inc.). Anti-lamin B1 (cat. no. 66095-1-Ig; 1:5,000; ProteinTech Group, Inc.) and anti-GAPDH (cat. no. 60004-1-Ig; 1:2,000; ProteinTech Group, Inc.) were used to verify equal protein loading. Following washing three times in TBST, the membranes were incubated with horseradish peroxidase conjugated goat anti-rabbit (cat. no. ZB-5301; 1:10,000; OriGene Technologies, Inc.) and goat anti-mouse (cat. no. ZB-2305; 1:5,000; OriGene
Technologies, Inc.) secondary antibodies at room temperature for $1 \mathrm{~h}$.

The proteins were visualized using an enhanced chemiluminescence reagent (Beyotime Institute of Biotechnology). The integrated optical density (IOD) of each band was analyzed using Image-Pro Plus software v6.0 (National Institutes of Health.). Each TLR4 and I $\mathrm{B} \alpha$ band value was normalized as the ratio of the IOD to the GAPDH band. Each NF- $\kappa$ B p65 band value was normalized as the ratio of the IOD to the lamin B1 band.

Statistical analysis. Statistical analyses were performed by SPSS v17.0 software (SPSS, Inc.). Graphs were generated using GraphPad Prism 5.2 software (GraphPad Software, Inc.). All data were presented as the mean value \pm standard deviation. Multiple comparisons were evaluated by one-way analysis of variance followed by the Student-Newman-Keuls and least significant difference post hoc tests. The Dunnett method was used for comparisons with the control group. $\mathrm{P}<0.05$ was considered to indicate statistical significance.

\section{Results}

GES-1 cell viability and growth rate following incubation with probiotics and CFS. The morphological characteristics of the probiotics and $H$. pylori were first evaluated following Gram staining (Fig. 1). The probiotics in this study were all Gram-positive bacteria. L. acidophilus was chain rod shaped, $L$. bulgaricus, B. longum and B. licheniformis were long rod shaped, B. infantis and L. salivarius were short rod shaped. C. butyricum contained giant spore and was enlarged at one end in a drum-hammer shape. H. pylori was a gram-negative bacterium, which is S-shaped or spiral. Furthermore, the viability of GES-1 cells incubated with CFS and different titers of probiotics (MOI of 100 and 1,000) was determined by assessing the percentage of cells not stained with trypan blue following 2, 4, 6 and $8 \mathrm{~h}$ of incubation. At a MOI of 100 , the cytotoxicity results indicated that the CFS of L. acidophilus, L. bulgaricus, L. salivarius, C. butyricum, $B$. infantis and B. longum were toxic to GES-1 cells. The CFS of $B$. licheniformis did not show any toxicity towards GES-1 cells with an average survival rate at $8 \mathrm{~h}$ of $96 \%$. L. acidophilus, L. bulgaricus, L. salivarius, Clostridium butyricum, Bifidobacterium infantis, Bifidobacterium longum and B. licheniformis did not show any toxicity towards GES-1 cells after $4 \mathrm{~h}$ of incubation, with an average survival rate of $97 \%$ and no significant differences between these groups and the control (Fig. 2A). However, GES-1 cell viability decreased gradually after $4 \mathrm{~h}$. At $6 \mathrm{~h}$, the most significant decrease in viability was observed in B. longum-treated cells, which had a $92 \%$ survival rate. Notably, the viability of these cells was significantly lower compared with the cells treated with the other six bacteria $(\mathrm{P}<0.05$; Fig. $2 \mathrm{~A})$. GES -1 cell viability following $B$. licheniformis treatment decreased at the slowest rate, with an average survival rate of $99.7 \%$. This was significantly higher than the survival rate of the cells treated with other bacteria $(\mathrm{P}<0.05$; Fig. 2A). There was no significant differences in the average GES-1 survival rates following treatment with L. acidophilus, L. bulgaricus, L. salivarius, C. butyricum, B. longum and B. infantis at $6 \mathrm{~h}$. At $8 \mathrm{~h}$, the 
Table I. Details of probiotic strains.

\begin{tabular}{llc}
\hline Species & Strain & Product \\
\hline Lactobacillus acidophilus & CGMCC0460.2 & Siliankang \\
Bifidobacterium infantis & CGMCC0460.1 & Siliankang \\
Bifidobacterium longum & NQ1501 & Jinshuangqi \\
Lactobacillus bulgaricus & NQ2508 & Jinshuangqi \\
Clostridium butyricum & CGMCC N0.0313-1 & Changlekang \\
Bacillus licheniformis & CMCC63516 & Zhengchangsheng \\
Lactobacillus salivarius & ATCC11741 & Taiwan Yaxin \\
\hline
\end{tabular}
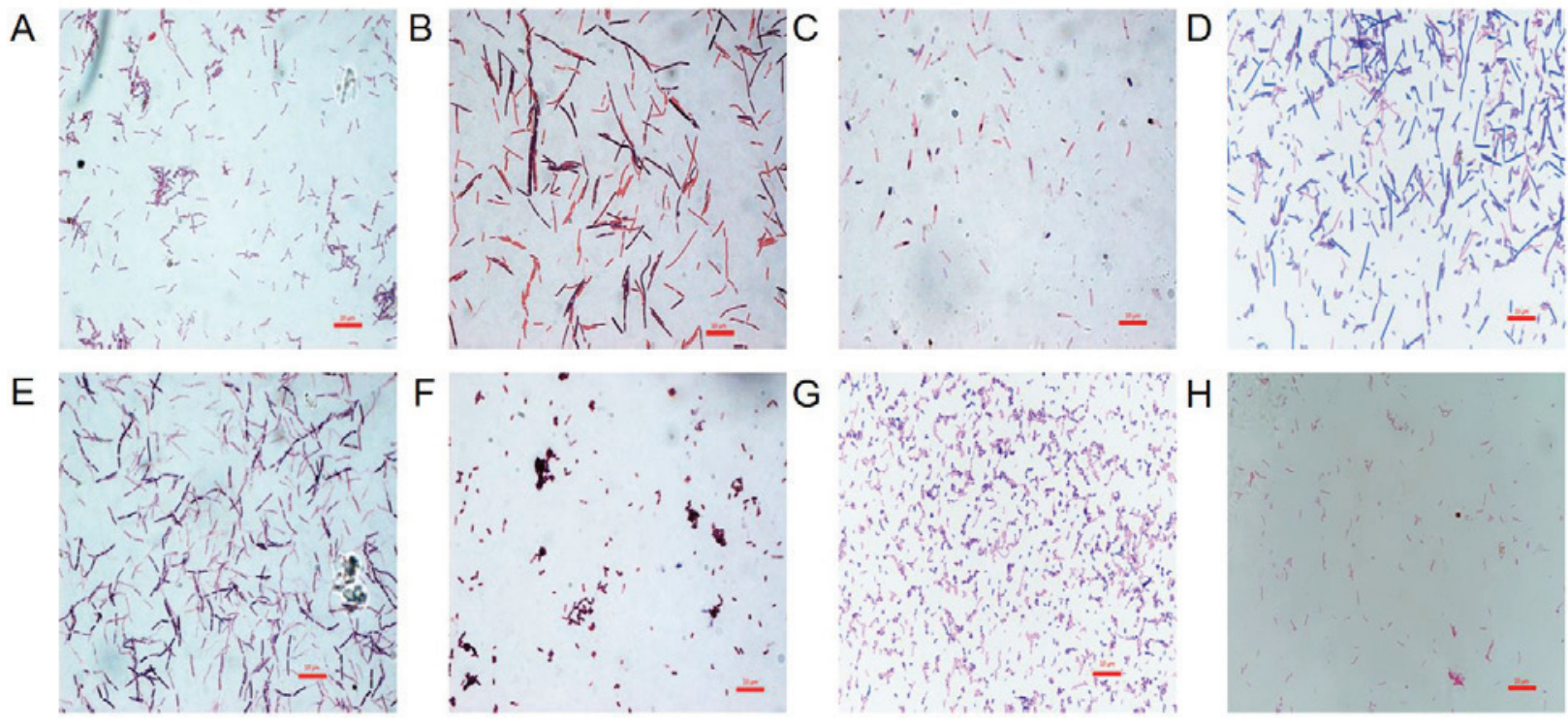

Figure 1. Morphological characteristics of various probiotic strains and H. pylori. (A) Lactobacillus acidophilus, (B) Lactobacillus bulgaricus, (C) Clostridium butyricum, (D) Bifidobacterium longum, (E) Bacillus licheniformis, (F) Lactobacillus salivarius, (G) Bifidobacterium infantis and (H) H.pylori gram staining (red or violet) micrographs under oil immersion (magnification, x1,000). H. pylori, Helicobacter pylori.

survival rate of the GES-1 cells decreased further with cells treated with L. bulgaricus, demonstrating significantly lower survival rate $(82.3 \%)$ compared with the cells treated with the other six probiotics $(\mathrm{P}<0.05$; Fig. $2 \mathrm{~A})$. Furthermore, the survival rate of cells treated with $B$. licheniformis was significantly increased $(96.7 \%)$ at $8 \mathrm{~h}$ compared with cells treated with the other six bacteria $(\mathrm{P}<0.05$; Fig. $2 \mathrm{~A})$.

At a MOI of 1,000, all seven probiotic strains exhibited no toxicity towards GES-1 cells at $2 \mathrm{~h}$ (Fig. 2B). However, GES-1 cell viability decreased following $4 \mathrm{~h}$ of incubation, with cells treated with L. bulgaricus (10.4\% at $4 \mathrm{~h}$ ) exhibiting significantly reduced viability compared with cells treated with the other six bacterial strains $(\mathrm{P}<0.05$; Fig. $2 \mathrm{~B})$. GES-1 cell viability following $B$. licheniformis treatment demonstrated the slowest decrease, with the average survival rate of cells $100 \%$ at $4 \mathrm{~h}$, which was significantly higher when compared with cells treated with the other bacterial strains $(\mathrm{P}<0.05$; Fig. 2B). The viability of B. licheniformis-treated GES-1 cells decreased significantly after $6 \mathrm{~h}$ compared with the control group $(\mathrm{P}<0.05$; Fig. $2 \mathrm{~B})$. Furthermore, the viability of these cells was $42.7 \%$ at $8 \mathrm{~h}$, whereas GES-1 cells treated with the other six bacteria did not survive past $8 \mathrm{~h}$. There were no significant differences between L. acidophilus-, L. salivarius-, B. longum-, B. infantum- and C. butyricum-treated cells (Fig. 2B). The probiotic half maximal inhibitory concentration $\left(\mathrm{IC}_{50}\right)$ for each group is listed in Table II, with B. longum demonstrating the lowest $\mathrm{IC}_{50}$ and $B$. licheniformis demonstrating the highest $\mathrm{IC}_{50}$.

Adhesion of probiotics to GES-1 cells. Probiotics adhered to GES-1 cells with different cell adhesion indexes and cell adhesion rates (Table III; Fig. 3). Staining of GES-1 cells for each probiotic group varied because metabolites produced by different probiotics were able to change the $\mathrm{pH}$ values of the culture medium, thereby affecting viability and staining (28). The $\mathrm{pH}$ values of the culture medium were $\mathrm{pH} 4$ (L.acidophilus), pH 5 (L. bulgaricus), pH 3.8 (B. infantis), pH 4.2 (B. longum), $\mathrm{pH} 4.8$ (L. salivarius), $\mathrm{pH} 5.5$ (C. butyricum) and $\mathrm{pH} 6.8$ (B. licheniformis).

As indicated in Fig. 4, the cell adhesion index was consistent with the cell adhesion rate, with the highest to lowest results as follows: L. acidophilus $>$ L. bulgaricus $>$ 

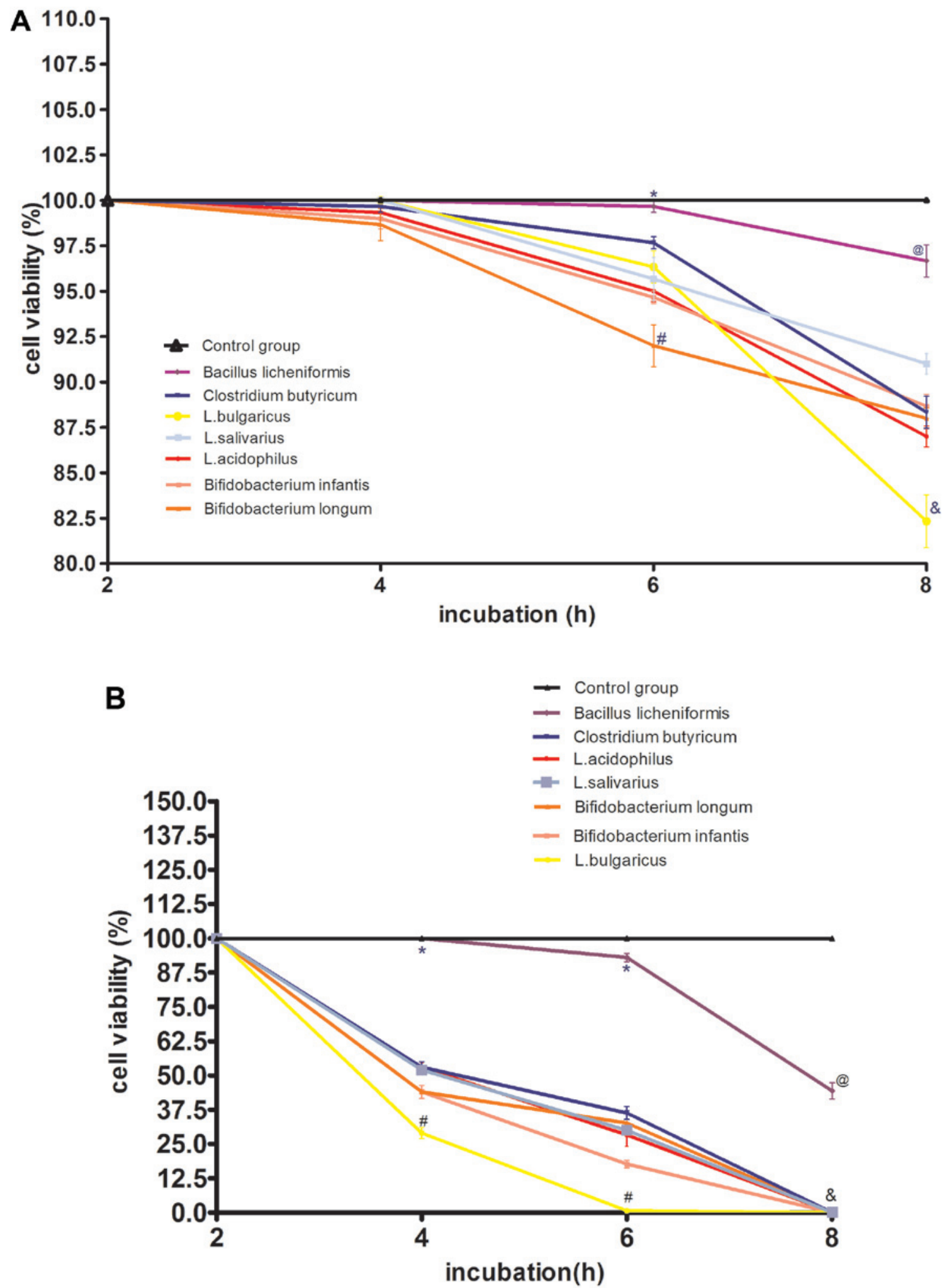

Figure 2. Effect of various probiotics strains on GES-1 cell viability. (A) GES-1 cell viability following culture with L. acidophilus, L. bulgaricus, L. Osalivarius, Clostridium butyricum, Bifidobacterium longum, Bifidobacterium infantis or Bacillus licheniformis at a MOI of 100 and (B) MOI of 1,000. (A) " $\mathrm{P}<0.05$ vs. L. acidophilus, L. bulgaricus, L. salivarius, Clostridium butyricum, Bifidobacterium longum, Bifidobacterium infantis; ${ }^{\#} \mathrm{P}<0.05$ vs. L. acidophilus, L. bulgaricus, L. salivarius, Clostridium butyricum, Bifidobacterium infantis, Bacillus licheniformis and control group; ${ }^{\circledR} \mathrm{P}<0.05$ vs, L. acidophilus, L. bulgaricus, L. salivarius, Clostridium butyricum, Bifidobacterium infantis, Bifidobacterium longum and control group; ${ }^{\circledR} \mathrm{P}<0.05$ vs. L. acidophilus, L. salivarius, Clostridium butyricum, Bifidobacterium infantis, Bifidobacterium longum, Bacillus licheniformis and control group. (B) ${ }^{*} \mathrm{P}<0.05$ cells vs. L. acidophilus, L. bulgaricus, L. salivarius, Clostridium butyricum, Bifidobacterium longum, Bifidobacterium infantis; ${ }^{\prime} \mathrm{P}<0.05$ vs. L. acidophilus, L. salivarius, Clostridium butyricum, Bifidobacterium infantis, Bifidobacterium longum, Bacillus licheniformis and control group; ${ }^{\circledR} \mathrm{P}<0.05 \mathrm{vs}$. L. acidophilus, L. bulgaricus, L. salivarius, Clostridium butyricum, Bifidobacterium infantis, Bifidobacterium longum and control group; ${ }^{\&} \mathrm{P}<0.05$ cells treated with L. bulgaricus, L. acidophilus, L. salivarius, Clostridium butyricum, Bifidobacterium infantis, Bifidobacterium longum vs. Bacillus licheniformis and control group. MOI, multiplicities of infection; L, Lactobacillus. 
B. infantis $>B$. longum $>L$. salivarius $>$ B. licheniformis $>$ $C$. butyricum. There was no significant difference in the cell adhesion index between $C$. butyricum and B. licheniformis (Fig. 4A); however, there were significant differences between the other five bacterial groups when compared with each other $(\mathrm{P}<0.05$; Fig. 4A). There was no significant difference in the cell adhesion rate between L. bulgaricus and L. acidophilus. In addition, no significant differences in the cell adhesion rate were observed between $B$. longum, C. butyricum, B. licheniformis and L. salivarius (Fig. 4B).

Live probiotics and CFS inhibit H. pylori growth. CFS from probiotic culture and live probiotics were screened for inhibitory effects against HP021 by measuring the diameters of inhibitory growth zones on agar plates (Table IV). Fresh MRS medium, used as a negative control, also exhibited significant activity against HP021 and formed inhibition zones of $27 \mathrm{~mm}$, which was larger than all the tested probiotics $(\mathrm{P}<0.05$; Table IV). This suggested that there were likely unknown anti-HP substances in MRS medium. Probiotics consumed some of the anti-HP substances of MRS, and likely secreted some anti-HP substances. Live L. bulgaricus demonstrated significantly greater anti- $H$. pylori activity compared with the other live probiotics, with inhibition zones of $\sim 25 \mathrm{~mm}(\mathrm{P}<0.05$; Table IV). Live B. licheniformis did not display any anti-H.pylori activity. By contrast, there were no significant differences in inhibition of $H$. pylori growth by live L. acidophilus, B. infantis, $B$. longum, L. salivarius and $C$. butyricum. The CFS from all the probiotics also inhibited H. pylori activities; however, there were no significant differences between the probiotic groups (Table IV). Similar results were observed when $H$. pylori ATCC43504 was used (data not shown).

Probiotics and CFS suppress adhesion of H. pylori to GES-1 cells. The urease activity of HP021 and ATCC43504 were examined to evaluate the effect of CFS and probiotics on HP021 and H. pylori ATCC43504 adherence to GES-1 cells. The adherence rate of $H$. pylori was $100 \%$ without probiotic or CFS treatment. Results indicated that pre- or post-treatment with B. licheniformis CFS did not reduce the adhesion of $H$. pylori to GES-1 cells compared with HP group (Fig. 5A). However, urease activity was significantly reduced following probiotic treatment, with the exception of C. butyricum and B. licheniformis treatment compared with the HP group (Fig. 5A). No significant differences between the two $H$. pylori strains were found (the data not shown). The adherence rate of $H$. pylori dropped to $\sim 50 \%$ with L.acidophilus treatment. Compared with non-treated cells, the adherence rate of HP021 did not decrease with C. butyricum or B. licheniformis treatment (Fig. 5B). These results demonstrated that pre-treatment with L. acidophilus, L. bulgaricus, L. salivarius, B. infantis and B. longum inhibited the adherence of $H$. pylori to GES-1 cells.

Certain probiotics significantly affect $I L-8$ production in GES-1 cells. Under normal physiological conditions, GES-1 cells secrete a small amount of IL-8 (29). The addition of HP-LPS to GES-1 cells for $6 \mathrm{~h}$ significantly increased the IL-8 levels compared with non-treated cells $(\mathrm{P}<0.05$; Fig. 6). No decrease in IL- 8 secretion following treatment with the CFS of B. licheniformis was observed compared with HP-LPS
Table II. GES-1 cell growth rate in the presence of various probiotic strains.

Half maximal inhibitory concentration

Probiotics (colony-forming units)

\begin{tabular}{lc}
\hline Bifidobacterium longum & $6.56 \times 10^{7}$ \\
Bifidobacterium infantis & $6.76 \times 10^{7}$ \\
Lactobacillus acidophilus & $8.57 \times 10^{7}$ \\
Lactobacillus salivarius & $1.55 \times 10^{8}$ \\
Lactobacillus bulgaricus & $2.09 \times 10^{8}$ \\
Clostridium butyricum & $3.0 \times 10^{8}$ \\
Bacillus licheniformis & $3.33 \times 10^{9}$ \\
\hline
\end{tabular}

Table III. Cell adhesion index and adhesion rate at the same concentration onto GES-1 cells.

\begin{tabular}{lcc}
\hline Probiotic strain & $\begin{array}{c}\text { Adhesion } \\
\text { index }(\%)\end{array}$ & $\begin{array}{c}\text { Adhesion } \\
\text { rate }(\%)\end{array}$ \\
\hline Lactobacillus acidophilus & $891.2 \pm 24.35$ & $56.6 \pm 8.35$ \\
Bifidobacterium infantis & $394.4 \pm 31.00$ & $37.8 \pm 7.12$ \\
Bifidobacterium longum & $328.2 \pm 23.04$ & $21.2 \pm 5.12$ \\
Clostridium butyricum & $24.4 \pm 12.78$ & $11.2 \pm 0.84$ \\
Bacillus licheniformis & $38.00 \pm 7.97$ & $17.8 \pm 4.60$ \\
Lactobacillus bulgaricus & $499.2 \pm 27.83$ & $50.0 \pm 8.12$ \\
Lactobacillus salivarius & $229.8 \pm 22.19$ & $20.6 \pm 5.41$ \\
\hline
\end{tabular}

group. However, following pre-treatment with $L$. bulgaricus and L. salivarius, there was a significant decrease in IL-8 secretion induced by HP-LPS compared with HP-LPS group ( $\mathrm{P}<0.05$; Fig. 6). Notably, IL-8 levels following HP-LPS plus L. acidophilus, B. infantis or B. longum treatment were higher compared with HP-LPS only treatment.

Probiotics attenuate the TLR4-NF- $\mathrm{B}$ p65 signaling pathway following HP-LPS activation. To explore the molecular mechanism of $H$.pylori on GES-1 growth, expression levels of markers associated with inflammation, TLR-4, I $\kappa \mathrm{B} \alpha$ and NF- $\kappa \mathrm{B}, \mathrm{p} 65$ were detected. H. pylori ATCC43504 contains CagA protein that induces activation of NF- $\kappa$ B and IL-8 whereas HP021 does not contain CagA protein. Therefore, H. pylori ATCC43504 was selected for the NF- $\kappa$ B activation and IL- 8 production experiment. L. bulgaricus reduced IL-8 production most significantly. Therefore, L. bulgaricus was selected for the $\mathrm{NF}-\kappa \mathrm{B}$ activation experiment. Treatment of GES-1 cells with 7,000 EU/ml of HP-LPS upregulated the expression of TLR-4, increased the degradation of $\mathrm{I} \kappa \mathrm{B} \alpha$ and induced the translocation of NF- $\kappa \mathrm{B}$ p65 into nucleus in a time-dependent manner (Fig. 7A and B). Pre-treatment for $2 \mathrm{~h}$ with viable L. bulgaricus (MOI of 100) significantly inhibited the effects of HP-LPS on

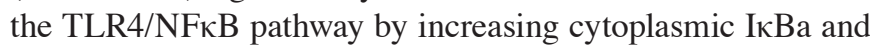
decreasing nuclear NF- $\kappa$ B p65 levels (Fig. 7C-E). The levels 

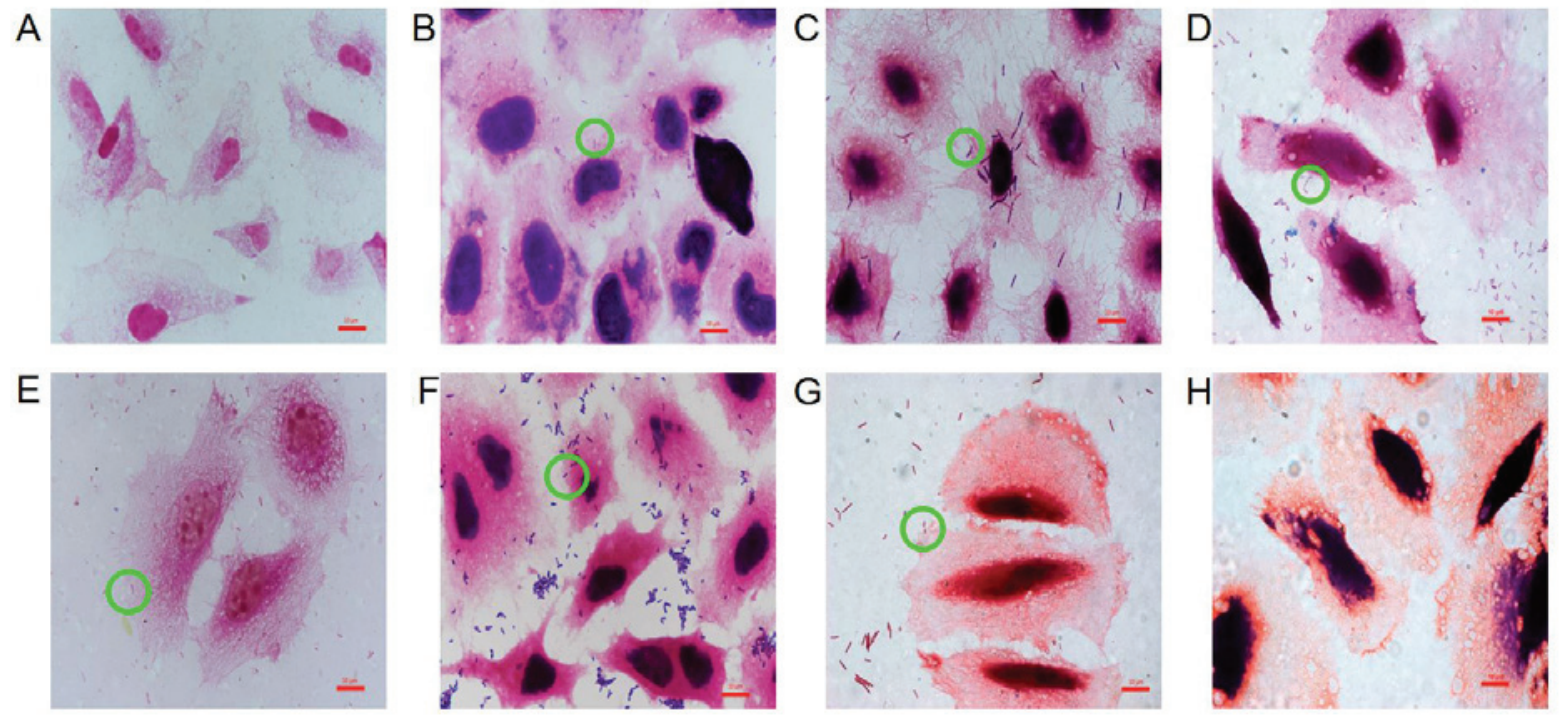

Figure 3. Binding of various probiotic strains to GES-1 cells. (A) Micrographs demonstrating gram staining of the control group with no probiotics. (B) GES-1 cells cultured with Lactobacillus acidophilus, (C) Lactobacillus bulgaricus, (D) Lactobacillus salivarius, (E) Bifidobacterium longum, (F) Bifidobacterium infantis, (G) Bacillus licheniformis or (H) Clostridium butyricum following Gram staining (red or violet). Green circles highlight probiotics that have adhered to GES-1 cells.

of NFKB and TLR-4 in L. bulgaricus pre-treatment 60 and 120 min groups were significantly lower than those of HP-LPS 60 and 120 mins groups, respectively $(\mathrm{P}<0.05$; Fig. $7 \mathrm{C}$ and $\mathrm{E})$. The level of IкB $\alpha$ in L. bulgaricus pre-treatment 120 min group was significantly higher than HP-LPS 120 min group $(\mathrm{P}<0.05$; Fig. 7D). These results indicated that the TLR4/NF- $\mathrm{KB}$ signaling pathway may be a critical target for probiotics to alter GES-1 cell biological functions.

\section{Discussion}

The present study assessed the effects of live probiotics and their CFS on $H$. pylori growth, adherence to gastric epithelial cells and $H$. pylori-induced inflammation. The findings demonstrated that $L$. acidophilus and L. bulgaricus significantly inhibited the adherence of $H$. pylori to GES-1 cells and also decreased IL-8 production by GES-1 cells following stimulation with HP-LPS In addition, $L$. bulgaricus inhibited the TLR $4 / \mathrm{I} \kappa \mathrm{B} \alpha / \mathrm{NF} \kappa \mathrm{B}$ signaling pathway in a time-dependent manner.

$H$. pylori causes gastritis, as well as gastric and duodenal ulcers $(2,30)$. In the past few decades, H. pylori treatment has improved due to the administration of PPI plus antibiotics. However, the emergence of drug-resistant $H$. pylori strains has complicated the eradication of the bacteria. Therefore, research is focusing on developing new strategies for treating H. pylori. Recent clinical trials have demonstrated that the administration of certain exogenous probiotics may improve the eradication of $H$. pylori (31). In addition, some probiotic strains can attenuate the mucosal inflammation induced by H. pylori (32). However, the molecular mechanism of these biological effects remains unclear.

The present study identified that the anti- $H$. pylori effects of live probiotics or their CFS were highly strain dependent. Seven probiotic strains commonly used in clinical settings were chosen. The H. pylori standard strain (ATCC43504), containing CagA and VacA virulence factors, and the clarithromycin and levofloxacin-resistant HP021 strain, originally isolated from the gastric mucosa of a patient, were also investigated. Results revealed that all seven probiotics significantly affected GES-1 cell viability following longer incubation times and higher MOIs. The CFS of Lactobacillus culture is a 96-h fermentation product containing high concentrations of acetic acid and other bactericidal substances. The present study determined that Lactobacillus CFS has a $\mathrm{pH}$ of 2, which was toxic to gastric epithelial cells in vitro. GES-1 cell death occurred within $2 \mathrm{~h}$ when treated with L.acidophilus, B. infantis, B. longum, L. salivarius, L. bulgaricus and C. butyricum CFS. Only B. licheniformis CFS had a $\mathrm{pH}$ of 7 therefore, was not considered toxic to GES-1 cells. Hence, only $B$. licheniformis CFS was selected for investigation into the adhesion of $H$. pylori to GES-1 cells and IL-8 production.

It is well established that adhesion to mucosal surfaces is a key step in the pathogenesis of H. pylori (33). The inhibition of $H$. pylori colonization by probiotics is strain specific. Chen et al (18) reported that CFS, live and dead lactobacilli inhibits $H$. pylori adhesion to SGC7901 cells. Hsieh et al (16) identified that L. johnsonii MH-68 and salicinius AP-32 effectively suppress $H$. pylori viability and reduce $H$. pylori colonization in the gastric mucosa of mice. Aiba et al (34) proved that $L$. salivarius is capable of producing a high amount of lactic acid and inhibiting the growth of $H$. pylori. In the present study, five probiotic strains adhered to GES-1 cells, with L. acidophilus displaying the strongest adhesive ability, followed by L. bulgaricus. However, C. butyricum and B. licheniformis did not demonstrate any notable adhesive ability. Further study is required to identify the mechanism of adhesion to the cell surface of L. acidophilus and L. bulgaricus. Pre-treatment with $L$. acidophilus, L. bulgaricus, $L$. salivarius, B. infantis 

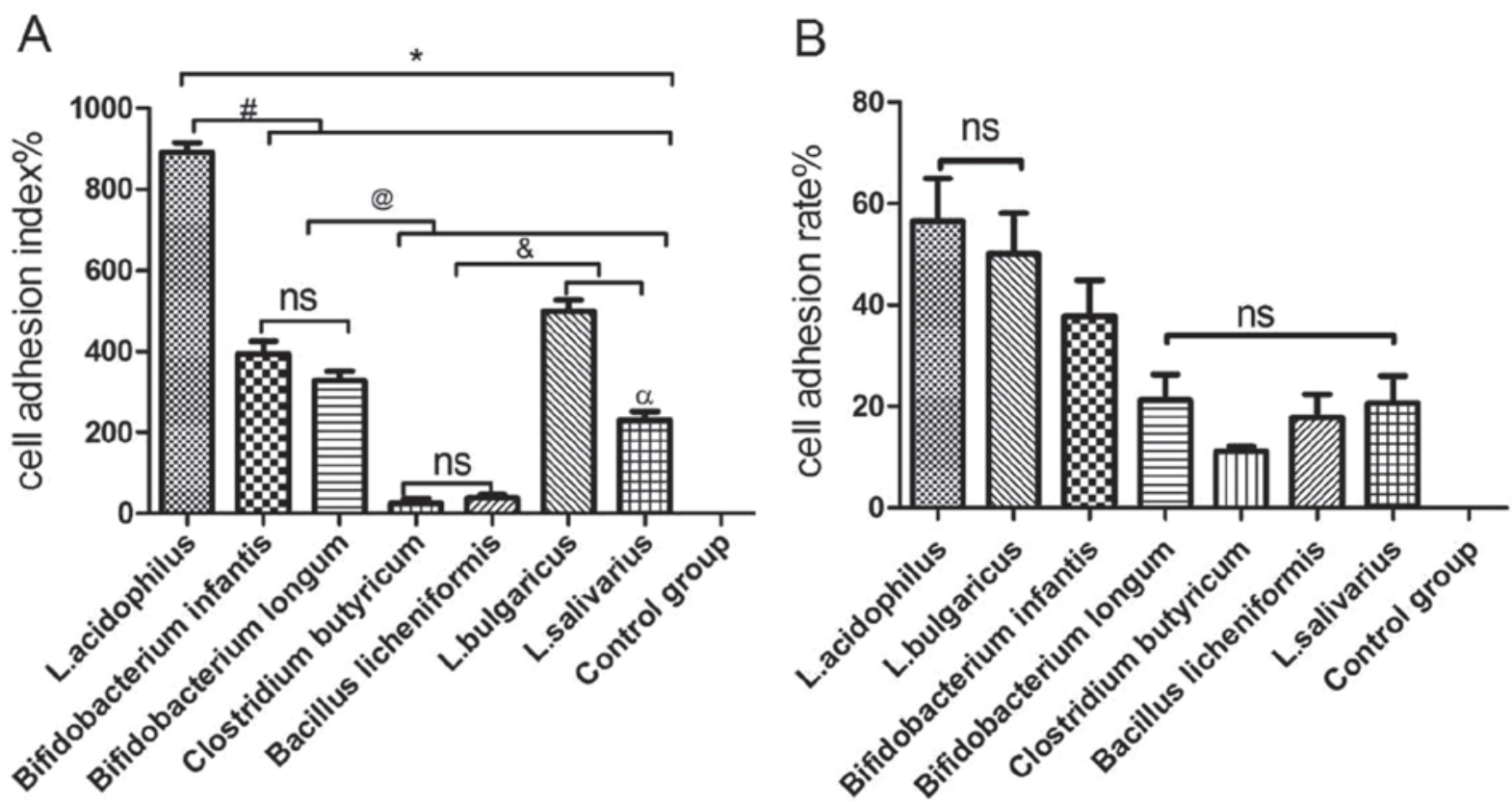

Figure 4. Adhesion of various probiotic strains to GES-1 cells. (A) Cell adhesion index of L.acidophilus, L. bulgaricus, L. salivarius, Clostridium butyricum, Bifidobacterium longum, Bifidobacterium infantis and Bacillus licheniformis to GES-1 cells. (B) Cell adhesion rate of L. acidophilus, L. bulgaricus, L. salivarius, Clostridium butyricum, Bifidobacterium longum, Bifidobacterium infantis and Bacillus licheniformis to GES-1 cells. " $\mathrm{P}<0.05$ vs. control group; ${ }^{\#} \mathrm{P}<0.05$ vs. L. acidophilus; ${ }^{\circledR} \mathrm{P}<0.05$ vs. Bifidobacterium infantis and Bifidobacterium longum; ${ }^{\circledR} \mathrm{P}<0.05$ vs. Clostridium butyricum and Bacillus licheniformis; ${ }^{a} \mathrm{P}<0.05$ vs. L. bulgaricus. L, Lactobacillus; $\mathrm{ns}$, not significant.

Table IV. HP021 growth in the presence of live probiotics and cell-free supernatant.

\begin{tabular}{lcc}
\hline & \multicolumn{2}{c}{ Average zone of inhibition (mm) } \\
\cline { 2 - 3 } Probiotic strain & Live probiotic & $\begin{array}{c}\text { Cell-free } \\
\text { supernatant }\end{array}$ \\
\hline Lactobacillus acidophilus & $20.33 \pm 1.53$ & $21.00 \pm 1.00$ \\
Bifidobacterium infantis & $20.00 \pm 1.00$ & $20.67 \pm 1.53$ \\
Bifidobacterium longum & $20.67 \pm 0.58$ & $21.91 \pm 0.58$ \\
Clostridium butyricum & $22.33 \pm 0.58$ & $21.33 \pm 0.58$ \\
Lactobacillus bulgaricus & $25.33 \pm 0.58^{\mathrm{b}}$ & $22.33 \pm 0.58$ \\
Bacillus licheniformis & 0 & $22.67 \pm 0.58$ \\
Lactobacillus salivarius & $21.00 \pm 1.00$ & $22.24 \pm 0.58$ \\
Man, Rogosa and & $27.00 \pm 1.00^{\mathrm{a}}$ & $27.00 \pm 1.00^{\mathrm{a}}$ \\
Sharpe broth & & \\
\hline
\end{tabular}

${ }^{\mathrm{a}} \mathrm{P}<0.05$ vs. L.acidophilus, L.bulgaricus, L.salivarius, Bifidobacterium infantis, Bifidobacterium longum, Bacillus licheniformis and Clostridium butyricum; ${ }^{\text {}} \mathrm{P}<0.05$ vs. L. acidophilus, L. salivarius, Bifidobacterium infantis, Bifidobacterium longum, Bacillus licheniformis and Clostridium butyricum.

and $B$. longum reduced the ability of $H$. pylori to adhere to GES-1 cells to differing extents. The inhibitory effects of L. acidophilus and L. bulgaricus were greater than L. salivarius, $B$. infantis and $B$. longum at the same concentration. Notably, the CFS of $B$. licheniformis did not reduce the adhesion of $H$. pylori to GES-1 cells compared with the HP group. The inhibitory effect of probiotic pre-treatment against $H$.pylori adherence is likely mediated via increasing production of mucin (35) or competition to bind $H$. pylori adhesion sites by probiotics (36). The adhesion of $H$. pylori to GES-1 cells was not inhibited when cells were treated with probiotics post-infection. Therefore, it appears that probiotics cannot reduce the adhesion rate of $H$. pylori when it is already adhered to gastric epithelial cells. Therefore, probiotics may be more effective in a preventive rather than therapeutic role.

Certain probiotic strains produce bactericidal substances that are either secreted into the culture supernatant or expressed on the cell surface, which can significantly inhibit $H$.pylori (37). The agar plate diffusion assays performed in the present study determined that live bacteria and their CFS from L. acidophilus, B. infantis, B. longum, L. bulgaricus, C. butyricum and L. salivarius inhibited the growth of $H$.pylori ATCC43504 and HP021 strains. Live B. licheniformis did not appear to inhibit the growth of H. pylori ATCC43504 or HP021, but the CFS of $B$. licheniformis did demonstrate anti- $H$. pylori properties. A possible mechanism of action is the secretion of lactic acid by the probiotics, as the metabolic end products of lactic acid fermentation and organic acids are capable of interfering with the growth of pathogens. Notably, El-Adawi et al (37) demonstrated that lactic acid may be a potent antimicrobial. However, $B$. licheniformis is not a lactic acid-producing bacterium, and the nature of the antimicrobial substance contained within its CFS requires further characterization.

Human immunity plays an important role in the development of clinical diseases. Pro-inflammatory cytokine production occurs during $H$. pylori infection, with the inflammatory reactions potentially leading to chronic inflammation rather than eliminating $H$. pylori $(38,39)$. The transcription factor NF- $\mathrm{BB}$ can be activated by IL-1 $\beta$, 

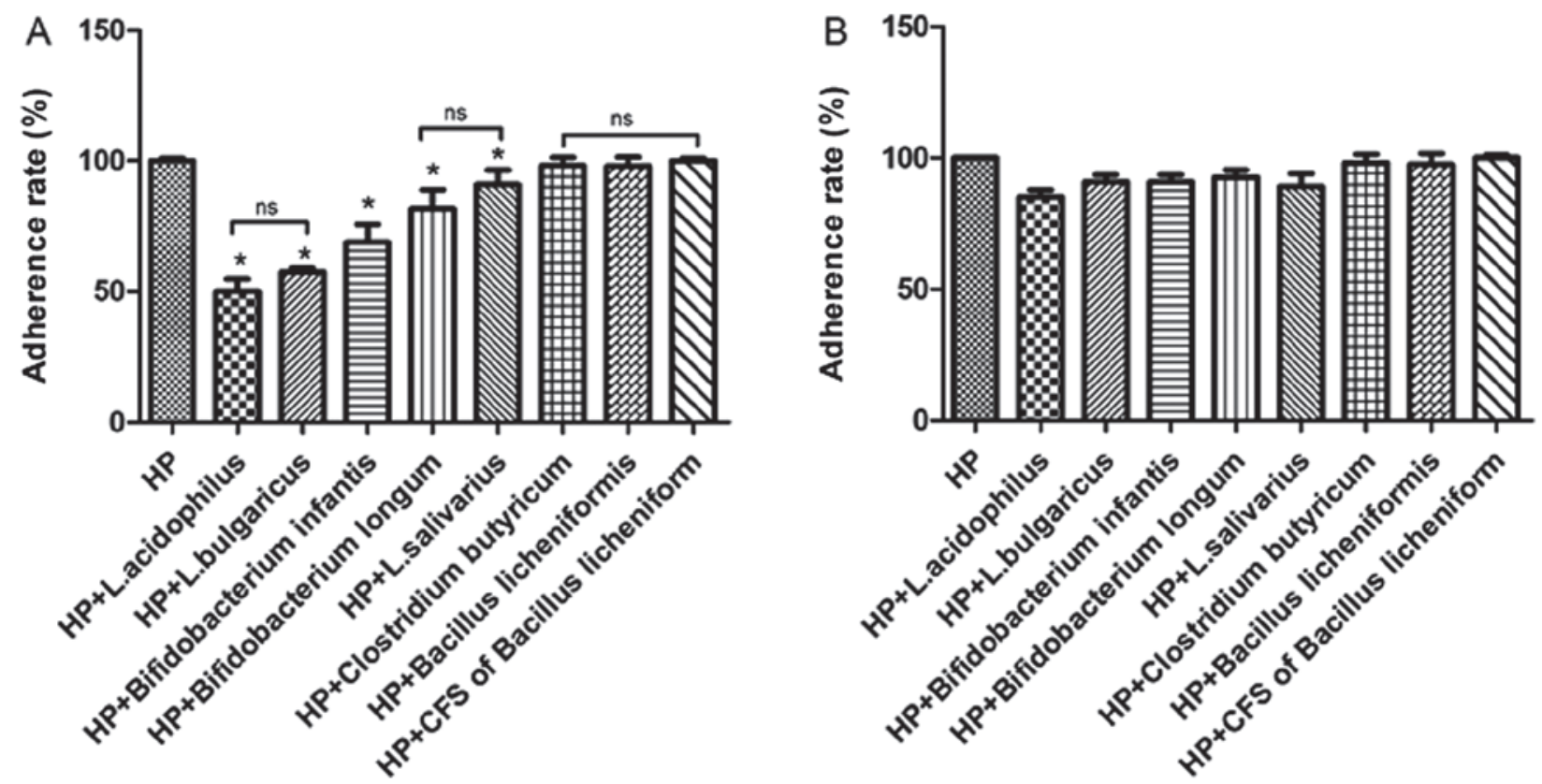

Figure 5. Adherence rate of HP to GES-1 cells in the presence of different probiotics at a MOI of 100. (A) Adherence rate of HP to GES-1 cells pretreated with L. acidophilus, L. bulgaricus, L. salivarius, Clostridium butyricum, Bifidobacterium infantis, Bifidobacterium longum, Bacillus licheniformis and CFS of Bacillus licheniformis. (B) Adherence rate of HP to GES-1 cells treated with L. acidophilus, L. bulgaricus, L. salivarius, Clostridium butyricum, Bifidobacterium infantis, Bifidobacterium longum, Bacillus licheniformis and CFS of Bacillus licheniformis following infection (post-treated). " $\mathrm{P}<0.05$ vs. HP group. HP, Helicobacter pylori; L, Lactobacillus; CFS, cell-free supernatant; ns, not significant.

LPS, peptidoglycan and tumor necrosis factor- $\alpha$ during H. pylori infection (40). NF- $\mathrm{\kappa B}$ is critical modulator of cytokine expression (41). TLRs are cell transmembrane and pathogen-associated molecular pattern receptors that have a central role in the recognition of microbial pathogens and may be a first line of immunity against $H$. pylori (42). HP-LPS-induced inflammation in gastric mucosa demonstrates similar pathological characteristics to the mucosal inflammation initiated by $H$. pylori infection (43). The present study determined that $H$. pylori infection induced TLR4 and IL-8 pro-inflammatory cytokine expression in vitro. The findings demonstrated that pre-treatment with viable $L$. bulgaricus for $2 \mathrm{~h}$ prevented TLR4 signaling and IL- 8 production stimulated by HP-LPS. This strongly supports the hypothesis that certain soluble proteins secreted by L. bulgaricus and/or cell-bound components of L. bulgaricus exert inhibitory effects on the TLR4 signaling pathways in GES-1 cells. Other cytokines such as IL-1 $\beta$, IL-10, IL-6 and Smad family member 7 are also involved in the response of $H$. pylori to epithelial cells $(17,44)$. The present study suggested that suppression of the TLR4/NF- $\mathrm{KB}$ signaling pathway occurred in a time-dependent manner and was mediated through the stabilization of $I \kappa B \alpha$.

In conclusion, the present study identified that two probiotic strains, L. acidophilus and L. bulgaricus, were effective in reducing the $H$. pylori load. One possible mechanism of L. bulgaricus on H.pylori activity was implied to be via modulation of the TLR4/IкB $\alpha / \mathrm{NF}-\kappa \mathrm{B}$ signaling pathway. Considering the safety and health function of probiotics, food containing L. acidophilus and L. bulgaricus may have potential as an adjuvant therapy for gastric diseases caused by $H$. pylori, and displays promise as a preventive measure against $H$. pylori infection.

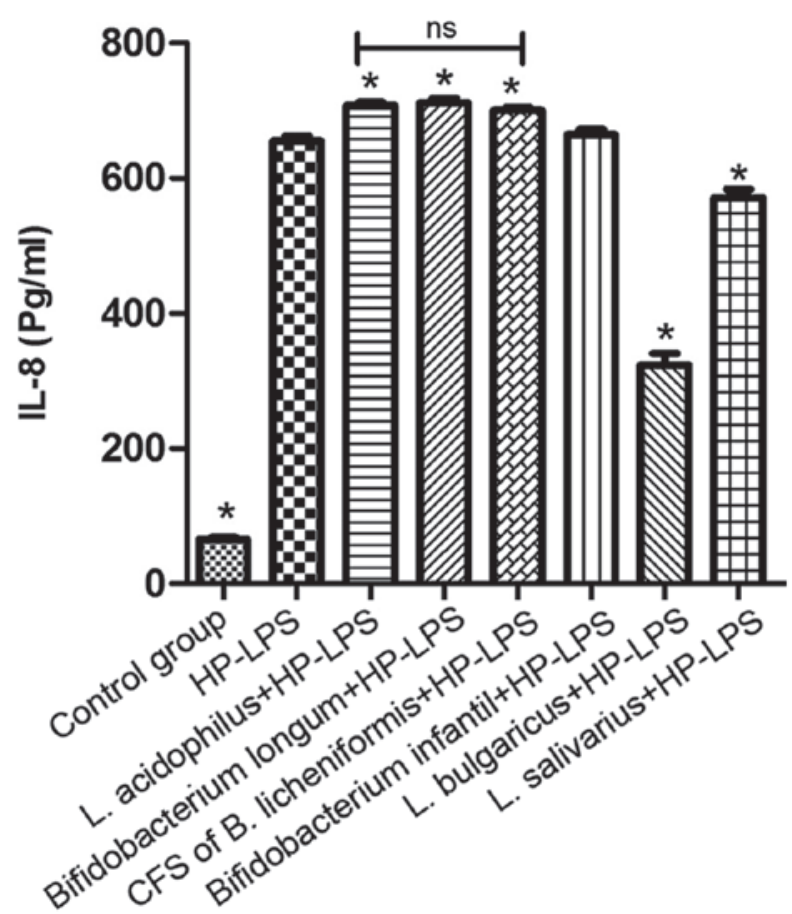

Figure 6. Effect of L. acidophilus, L. bulgaricus, L. salivarius, Bifidobacterium infantis, Bifidobacterium longum CFS of Bacillus licheniformis on IL-8 production following HP-LPS treatment. "P<0.05 vs. HP-LPS. HP, Helicobacter pylori; LPS, lipopolysaccharide; IL, interleukin; NS, not significant, L, Lactobacillus.

\section{Acknowledgements}

The authors would like to thank Professor Jianzhong Zhang from the China Center of Disease Prevention Center for the 

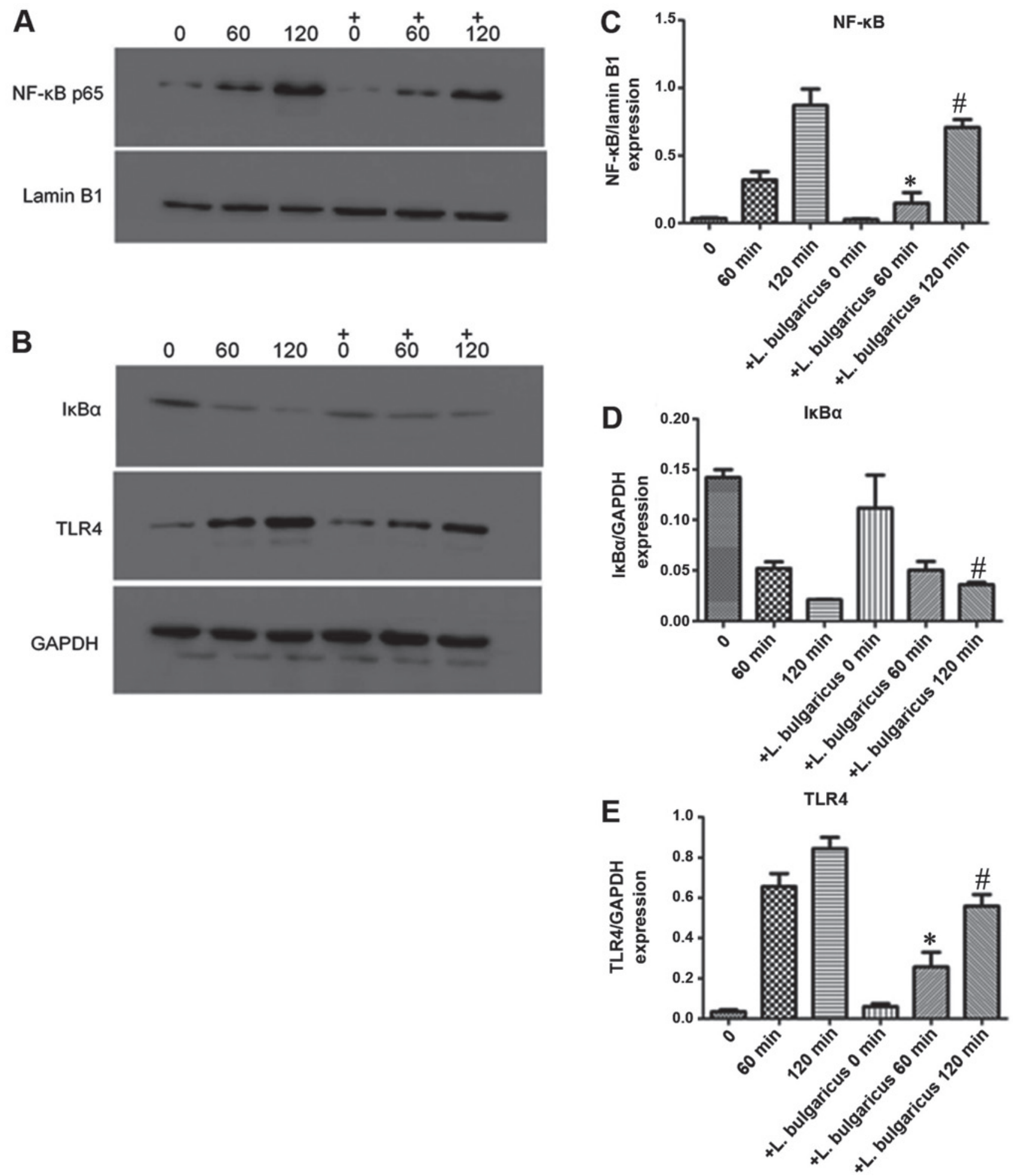

Figure 7. TLR4, IKB $\alpha$ and NF- $\mathrm{KB}$ p65 expression by GES-1 cells treated with HP-LPS in the absence or presence of live L. bulgaricus. (A) Representative

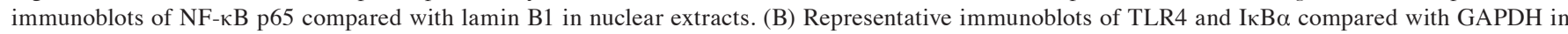

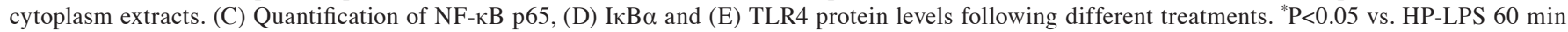

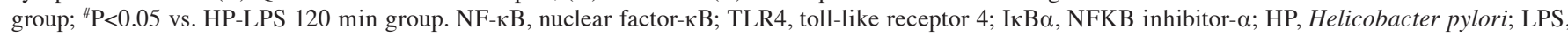
lipopolysaccharide; L, Lactobacillus.

H. pylori culture technical support.

\section{Funding}

No funding was received.

\section{Availability of data and materials}

The datasets generated and/or analyzed during the current study are available from the corresponding author on reasonable request. 


\section{Authors' contributions}

SHY, ZL and GLH performed the experiments and analyzed data. LY designed the experiment, analyzed data and wrote the manuscript. LDY analyzed data and was involved in discussions about the manuscript. All authors read and approved the final manuscript.

\section{Ethics approval and consent to participate}

The clinical study was approved by the Ethics Committee of Shengjing Hospital and the patient provided written informed consent.

\section{Patient consent for publication}

Not applicable.

\section{Competing interests}

The authors declare that they have no competing interests.

\section{References}

1. Warren JR and Marshall B: Unidentified curved bacilli on gastric epithelium in active chronic gastritis. Lancet 1: $1273-1275,1983$.

2. Kusters JG, van Vliet AH and Kuipers EJ: Pathogenesis of Helicobacter pylori infection. Clin Microbiol Rev 19: 449-490, 2006.

3. Salama NR, Hartung ML and Müller A: Life in the human stomach: Persistence strategies of the bacterial pathogen Helicobacter pylori. Nat Rev Microbiol 11: 385-399, 2013.

4. Fock KM, Graham DY and Malfertheiner P: Helicobacter pylori research: Historical insights and future directions. Nat Rev Gastroenterol Hepatol 10: 495-500, 2013.

5. Todo K, Ohmae T, Osamura T, Imamura T and Imashuku S: Severe Helicobacter pylori gastritis-related thrombocytopenia and iron deficiency anemia in an adolescent female. Ann Hematol 95: 835-836, 2016.

6. Franchini M, Vescovi PP, Garofano $M$ and Veneri D: Helicobacter pylori-associated idiopathic thrombocytopenic purpura: A narrative review. Semin Thromb Hemost 38: 463-468, 2012.

7. Gao W, Cheng H, Hu F, Li J, Wang L, Yang G, Xu L and Zheng X: The evolution of Helicobacter pylori antibiotics resistance over 10 years in Beijing, China. Helicobacter 15: 460-466, 2010.

8. Chey WD, Leontiadis GI, Howden CW and Moss SF: ACG Clinical Guideline: Treatment of Helicobacter pylori Infection. Am J Gastroenterol 112: 212-239, 2017.

9. Graham DY, Fagoonee S and Pellicano R: Increasing role for modified bismuth-containing quadruple therapies for Helicobacter pylori eradication. Minerva Gastroenterol Dietol 63: 77-79, 2017.

10. Masannat Y and Nazer E: Pepto bismuth associated neurotoxicity: A rare side effect of a commonly used medication. W V Med J 109: 32-34, 2013.

11. Kafshdooz T, Akbarzadeh A, Majdi Seghinsara A, Pourhassan M, Nasrabadi HT and Milani M: Role of probiotics in managing of Helicobacter pylori infection: A review. Drug Res (Stuttg) 67: 88-93, 2017.

12. Urrutia-Baca VH, Escamilla-Garcia E, de la Garza-Ramos MA, Tamez-Guerra P, Gomez-Flores R and Urbina-Rios CS: In vitro antimicrobial activity and downregulation of Virulence gene expression on Helicobacter pylori by reuterin. Probiotics Antimicrob Proteins 10: 168-175, 2018.

13. Garcia-Castillo V, Zelaya H, Ilabaca A, Espinoza-Monje M, Komatsu R, Albarracín L, Kitazawa H, Garcia-Cancino A and Villena J: Lactobacillus fermentum UCO-979C beneficially modulates the innate immune response triggered by Helicobacter pylori infection in vitro. Benef Microbes 9: 829-841, 2018
14. Çekin AH, Şahintürk Y, Akbay Harmandar F, Uyar S, Yolcular BO and Çekin Y: Use of probiotics as an adjuvant to sequential $H$. pylori eradication therapy: Impact on eradication rates, treatment resistance, treatment-related side effects, and patient compliance. Turk J Gastroenterol 28: 3-11, 2017.

15. Marcial G, Villena J, Faller G, Hensel A and de Valdez GF: Exopolysaccharide-producing Streptococcus thermophilus CRL1190 reduces the inflammatory response caused by Helicobacter pylori. Benef Microbes 8: 451-461, 2017.

16. Hsieh PS, Tsai YC, Chen YC, Teh SF, Ou CM and King VA: Eradication of Helicobacter pylori infection by the probiotic strains Lactobacillus johnsonii MH-68 and L. salivarius ssp. salicinius AP-32. Helicobacter 17: 466-477, 2012.

17. Yang YJ, Chuang CC, Yang HB, Lu CC and Sheu BS: Lactobacillus acidophilus ameliorates $\mathrm{H}$. pylori-induced gastric inflammation by inactivating the $\operatorname{Smad} 7$ and $N F \kappa B$ pathways. BMC Microbiol 12: 38, 2012.

18. Chen X, Liu XM, Tian F, Zhang Q, Zhang HP, Zhang H and Chen W: Antagonistic activities of lactobacilli against Helicobacter pylori growth and infection in human gastric epithelial cells. J Food Sci 77: M9-M14, 2012.

19. Hassan ST and Šudomová M: Probiotics as dietary supplements for eradication of Helicobacter pylori infection in children: A role beyond infection. Children (Basel) 3: E27, 2016.

20. Lee CY, Shih HC, Yu MC, Lee MY, Chang YL, Lai YY, Lee YC, Kuan YH and Lin CC: Evaluation of the potential inhibitory activity of a combination of L. acidophilus, L. rhamnosus and L. sporogenes on Helicobacter pylori: A randomized double-blind placebo-controlled clinical trial. Chin J Integr Med 23: 176-182, 2017.

21. Peng YC, Ho SP, Shyu CL, Chang CS and Huang LR: Clarithromycin modulates Helicobacter pylori-induced activation of nuclear factor- $\kappa \mathrm{B}$ through classical and alternative pathways in gastric epithelial cells. Clin Exp Med 14: 53-59, 2014.

22. de Klerk N, Maudsdotter L, Gebreegziabher H, Saroj SD, Eriksson B, Eriksson OS, Roos S, Lindén S, Sjölinder H and Jonsson AB: Lactobacilli reduce Helicobacter pylori attachment to host gastric epithelial cells by inhibiting adhesion gene expression. Infect Immun 84: 1526-1535, 2016.

23. Deng X, Ma H, Yu Q, et al: In vitro investigate the role of the Lactobacillus from human and Lactobacillus Acidophilus on the growth of the Helicobacter pylori Sydney Strainl (SS1) and the effects of the adhesive ability to gastric epithelial cell. Sichuan Med J 36: 1256-1260, 2015.

24. Wang B, Wei H, Yuan J, Li Q, Li Y, Li N and Li J: Identification of a surface protein from Lactobacillus reuteri JCM1081 that adheres to porcine gastric mucin and human enterocyte-like HT-29 cells. Curr Microbiol 57: 33-38, 2008.

25. Amin M, Anwar F, Naz F, Mehmood T and Saari N: AntiHelicobacter pylori and urease inhibition activities of some traditional medicinal plants. Molecules 18: 2135-2149, 2013.

26. Sgouras D, Maragkoudakis P, Petraki K, Martinez-Gonzalez B, Eriotou E, Michopoulos S, Kalantzopoulos G, Tsakalidou E and Mentis A: In vitro and in vivo inhibition of Helicobacter pylori by Lactobacillus casei strain Shirota. Appl Environ Microbiol 70: 518-526, 2004.

27. Zhou C, Ma FZ, Deng XJ, Yuan H and Ma HS: Lactobacilli inhibit interleukin-8 production induced by Helicobacter pylori lipopolysaccharide-activated Toll-like receptor 4. World J Gastroenterol 14: 5090-5095, 2008.

28. Bettinger $\mathrm{C}$ and Zimmermann HW: New investigations on hematoxylin, hematein, and hematein-aluminium complexes. II. Hematein-aluminium complexes and hemalum staining. Histochemistry 96: 215-228, 1991.

29. Xu C, Wan Y, Guo T and Chen X: Effect of hydrogen sulfide on the expression of CSE, NF- $\kappa$ B, and IL- 8 mRNA in GES-1 cells with Helicobacter pylori infection. Zhong Nan Da Xue Xue Bao Yi Xue Ban 38: 977-983, 2013 (In Chinese).

30. Amieva M and Peek RM Jr: Pathobiology of Helicobacter pylori -induced gastric cancer. Gastroenterology 150: 64-78, 2016.

31. Oh B, Kim BS, Kim JW, Kim JS, Koh SJ, Kim BG, Lee KL and Chun J: The effect of probiotics on gut microbiota during the Helicobacter pylori eradication: Randomized controlled trial. Helicobacter 21: 165-174, 2016.

32. Panpetch W, Spinler JK, Versalovic J and Tumwasorn S: Characterization of Lactobacillus salivarius strains B37 and B60 capable of inhibiting IL-8 production in Helicobacter pylori -stimulated gastric epithelial cells. BMC Microbiol 16: 242, 2016.

33. De Falco M, Lucariello A, Iaquinto S, Esposito V, Guerra G and De Luca A: Molecular mechanisms of Helicobacter pylori pathogenesis. J Cell Physiol 230: 1702-1707, 2015. 
34. Aiba Y, Suzuki N, Kabir AM, Takagi A and Koga Y: Lactic acid-mediated suppression of Helicobacter pylori by the oral administration of Lactobacillus salivarius as a probiotic in a gnotobiotic murine model. Am J Gastroenterol 93: 2097-2101, 1998.

35. Mack DR, Michail S, Wei S, McDougall L and Hollingsworth MA: Probiotics inhibit enteropathogenic E. coli adherence in vitro by inducing intestinal mucin gene expression. Am J Physiol 276: G941-G950, 1999.

36. Valeur N, Engel P, Carbajal N, Connolly E and Ladefoged K: Colonization and immunomodulation by Lactobacillus reuteri ATCC 55730 in the human gastrointestinal tract. Appl Environ Microbiol 70: 1176-1181, 2004.

37. El-Adawi H, El-Sheekh M, Khalil M,El-Deeb N and Hussein M: Lactic acid bacterial extracts as anti- Helicobacter pylori: A molecular approach. Ir J Med Sci 182: 439-452, 2013.

38. Jang S, Kim J and Cha JH: Cot kinase plays a critical role in Helicobacter pylori -induced IL-8 expression. J Microbiol 55: 311-317, 2017.

39. Dixon BR, Radin JN, Piazuelo MB, Contreras DC and Algood HM: IL-17a and IL-22 induce expression of antimicrobials in gastrointestinal epithelial cells and may contribute to epithelial cell defense against Helicobacter pylori. PLoS One 11: e0148514, 2016.

40. Lee MH, Yang JY, Cho Y, Woo HJ, Kwon HJ, Kim DH, Park M, Moon C, Yeon MJ, Kim HW, et al: Inhibitory effects of Menadione on Helicobacter pylori growth and Helicobacter pylori -induced inflammation via NF- $\beta$ B inhibition. Int J Mol Sci 20: E1169, 2019.
41. Cha B, Lim JW and Kim H: Jak1/Stat3 is an upstream signaling of NF- $\mathrm{kB}$ activation in Helicobacter pylori -induced IL-8 production in gastric epithelial AGS cells. Yonsei Med J 56: 862-866, 2015.

42. Villena $J$ and Kitazawa $H$ : Modulation of intestinal TLR4-inflammatory signaling pathways by probiotic microorganisms: Lessons learned from Lactobacillus jensenii TL2937. Front Immunol 4: 512, 2014.

43. Stein SC, Faber E, Bats SH, Murillo T, Speidel Y, Coombs N and Josenhans C: Helicobacter pylori modulates host cell responses by CagT4SS-dependent translocation of an intermediate metabolite of LPS inner core heptose biosynthesis. PLoS Pathog 13: e1006514, 2017.

44. Yu HJ, Liu W, Chang Z, Shen H, He LJ, Wang SS, Liu L, Jiang YY, Xu GT, An MM and Zhang JD: Probiotic BIFICO cocktail ameliorates Helicobacter pylori induced gastritis. World J Gastroenterol 21: 6561-6571, 2015.

This work is licensed under a Creative Commons Attribution-NonCommercial-NoDerivatives 4.0 International (CC BY-NC-ND 4.0) License. 